\title{
EFFECT OF CLEOME GYNANDRA LEAF EXTRACT ON THE ESTROUS CYCLE AND HISTOLOGY OF THE OVARY AND UTERUS OF WISTAR ALBINO RATS
}

Lemuel Ann Monima ${ }^{1}$, Muhammad Buhari ${ }^{1}$, Sodiq Lawal ${ }^{1}$, Echoru Isaac ${ }^{1}$, Ssempijja Fred ${ }^{1}$, Owembabazi Elna $^{1}$, Bukenya Edmund ${ }^{1}$, Mario Edgar Fernandez Diaz ${ }^{1}$, Archibong Victor Bassey ${ }^{1}$, Kokas Ikwap ${ }^{2}$

${ }^{1}$ Department of Human Anatomy, Kampala International University, Western-Campus, P.O.Box 71, Ishaka Bushenyi, Uganda.

${ }^{2}$ School of Bio-Security, Biotechnical and Laboratory Sciences, College of Veterinary Medicine, Animal Resources and Bio-Security, Makerere University, P.O.Box 7062, Kampala, Uganda.

*Correspondence to Lemuel Ann Monima, Kampala International University, Western-Campus, P.O.Box 71, Ishaka Bushenyi, Uganda., +256703665972, annexdot5@gmail.com

\begin{abstract}
Cleome gynandra is a medicinal plant that is used all over Uganda to hasten childbirth because, it possesses the ability to contract the uterus. It is also used as an abortifacient in the first trimester. In this study, the effects of Cleome gynandra were investigated on the estrous cycle and the histology of the ovary and uterus of adult Wistar rat. Twelve adult female Wistar rats of $130-140 \mathrm{~g}$ average weight were used. These were divided into three groups of four animals each. Group A received distilled water only, while animals in groups $B$ and $C$ received $250 \mathrm{mg} / \mathrm{kg}$ body weight and $500 \mathrm{mg} / \mathrm{kg}$ body weight of extract, orally and daily respectively. Monitoring of estrous cycle continued throughout the three weeks of extract administration. After three weeks, the ovaries and uteri were excised and processed for histological examination. In the ovary, there was a reduction in number of primordia, primary, secondary and graafian follicles in the treated groups. Vacuolations were common to both the ovarian and uterine tissues of treated animals. The estrous cycle of Group B and $\mathrm{C}$, showed a mild disruption when compared to animals in Group A. The results showed that the plant extract studied, exerted negative influences on the estrous cycle and histology of the ovary and uterus of Wistar albino rats, suggesting a disturbance on the reproductive health of the animals. Further studies to determine the mechanism of action of Cleome gynandra on the ovary and uterus and the levels of FSH, LH, estradiol and progesterone is recommended.

Key Words: Cleome gynandra, estrous cycle, Wistar albino rats, ovarian follicles.
\end{abstract}

\section{INTRODUCTION}

The use of plants for medicinal and mythological purposes, and for solving problems related to ill health has been practiced in the African and other societies for many years (Mohammed et al., 2014). Some of the factors that help to increase the use of herbal medicines include its availability, cultural significance, history of known effectiveness, and most significantly, easy access compared to the modern pharmaceuticals (Thomford et al., 2015). Approximately, $40-50 \%$ of all marketed drugs are either obtained from herbs or their use is stirred by medicinal plants (Ekor, 2014). The World Health Organization approximates that $80 \%$ of the population in Africa depend on traditional medicines for their primary health care needs (WHO, 2005), this figure

Submitted $20^{\text {th }}$ September 2018. Published online $14^{\text {th }}$ January 2019. To cite: Lemuel AM, Muhammad B, Sodiq L, Echoru I, Ssempija F, Owembabazi E, Bukenya E, Mario EFD, Archibong VB, Kokas I. The gender and side asymmetry of length of the styloid process. Anatomy Journal of Africa. 8 (1): 1385 - 1394. 
increases to about $90 \%$ of the population in developing countries (Robinson and Zhang, 2011).

The female reproductive system is extremely sensitive to several factors such as the life style, radiation, drugs and toxicants (Fucic et al., 2012). Exposure to any of these and other factors could lead to congenital abnormalities in infants and even functional alterations in adults (Knapp et al., 2012). Any interference that alters the normal functioning of the organs of reproduction affects the ability of the animal to reproduce.

Cleome gynandra (C. gynandra), is a medicinal plant that belongs to the botanical family Capparaceae. Phytochemical screening of a methanolic extract of C. gynandra showed that the plant contains saponins, phenols, flavonoids, steroids and proteins, hence making it beneficial in the treatment of various diseases (Kalita, 2014). It is widely distributed across the world and is found all over the greater part of Africa (Mishra et al., 2011). It is seen mostly in waste land and is propagated by seeds that are widely dispersed, germinating during rainy season (Ekpong, 2009). C. gynandra is popularly known as Cat's whiskers in English and in Uganda, it is known as Ejjobyo in Luganda meaning 'bitter plant' (Moshi et al., 2012). Studies have shown that, several plants and plant products affect the female reproductive system in a number of ways. Previous studies have shown that, $\mathrm{C}$. gynandra has capacity to contract the uterus in rats (KamatenesiMugisha and Oryem-Origa, 2007). In their study, the oxytocic effect of C. gynandra on the uterus was tested in vitro. This, compliments the report of Singh et al. (2006), who listed C. gynandra as one of the several herbal medicines used to terminate pregnancy in Uganda. Despite the many uses of C. gynandra, its effects on the estrous cycle and on the histological organisation of the organs of the reproductive systems is not known. Hence, there is still need to explore and verify its nature in science and everyday traditional healthcare. Indeed, this research aims at finding some scientific basis of the effects of C. gynandra, on the estrous cycles, ovaries and uterus in Wistar albino rats.

\section{MATERIALS AND METHODS}

This was an experimental study to evaluate the effects of $\mathrm{C}$. gynandra aqueous leaf extract on the estrous cycle and the histology of the ovary and the uterus of laboratory Wistar albino rats (Rattus Norvegicus). Twelve (12) adult female Wistar rats, ten (10) weeks old, weighing between $130-140 \mathrm{~g}$, were purchased from the animal facility, of the Pharmacology Department, Kampala International University, Western campus. The animals were allowed to acclimatize for a period of two weeks before commencement of the experiment. The animals were kept in appropriate cages with wired open tops at constant temperature of $21+2^{\circ} \mathrm{C}$, with an alternate 12-hour light and dark cycle. Saw dust was used as beddings for the cages. The animals were given standard rat pellet diet obtained from Mice Meal LTD, Jinja, Uganda. They were also provided with distilled water. Animals were randomly assigned into three groups; A, B and C of four (4) animals per group with approximately equal mean body weight. Group A served as control and received $1 \mathrm{ml}$ of distilled water, while group $B$ and $C$ received extract at $250 \mathrm{mg} / \mathrm{kg} \mathrm{B.W}$ and $500 \mathrm{mg} / \mathrm{kg} \mathrm{B.W}$, orally and daily respectively.

The extract was prepared using the method described by Namulindwa et al. (2015), with slight modification. Briefly, fresh plant materials were harvested in November 2016, from gardens and open fields around the Kampala International University, Bushenyi District, in Western Uganda. The specimens were taken to a qualified Taxonomist for authentication at the Department of Botany, Faculty of Science, Mbarara University of Science and Technology, Uganda. It was identified as Cleome gynandra and issued with a collector number \#001, a sample of this was kept for future references.

The plants were washed thoroughly in running tap water and shade dried at room 
temperature for 14 days. Dried leaves were grinded into a fine powder using an electric blender and stored in air tight bottles until use. One hundred grams $(100 \mathrm{~g})$ of the powder, was macerated in 1 litre of distilled water and left on a mechanical shaker for 24 hours to permit complete extraction. The solution obtained was filtered repeatedly using a vacuum pump filter with Whatman filter paper No. 1, to obtain the filtrate. Thereafter, the mixture was concentrated by evaporating using a water bath at $60^{\circ} \mathrm{C}$ to a semi solid form of constant weight. The resulting extract was stored at $4^{\circ} \mathrm{C}$ in a refrigerator till further use.

The use of the aqueous extract for this study is designed to mimic human consumption of C. gynandra traditionally.

Vaginal smears of each rat were taken at approximately the same time between 7am and 9am every morning for five weeks ( 2 weeks before treatment and 3 weeks during treatment), to ensure regular estrous cycles. The materials used were $1 \mathrm{ml}$ rubber pipette, beakers, distilled water, glass slide and a light microscope. The animals were held in a supine position in one hand and with the other hand, using the rubber pipette, $0.5 \mathrm{ml}$ of distilled water was flushed into the vagina orifice twice. The vagina fluid was collected and carefully placed on the glass slide and prepared for microscopic examination (Goldman et al., 2007). The rubber pipette was thoroughly rinsed between lavages to remove any residual cells before using it for the next animal.

Staining of vaginal smears was adopted from the protocol described by Mclean et al. (2012). Exactly $0.1 \mathrm{~g}$ of crystal violet powder was added to $100 \mathrm{ml}$ of double distilled water $\left(\mathrm{ddH}_{2} \mathrm{O}\right)$ and mixed thoroughly. Crystal violet stain $(0.1 \%)$ was stored in a tightly sealed container at room temperature until needed. Using an eye dropper, crystal violet stain $(0.1 \%)$, was dropped on one side of the cover slip. Excessive fluid was drained from the edges of the slide using a filter paper, until the stain was evenly distributed across the slide. The stained smear was observed under the light microscope (Ultra Medical MDI, Guangzhou Keyeah Optics \& Electronics
Instrument Co. LTD, China), immediately for the proportion of nucleated epithelial cells, cornified epithelial cells and leukocytes. Following the method described by Tropp and Markus, (2001), animals whose vaginal smears contained predominately leukocytes $(60 \%)$ were classified as diestrus I or II. Smears that contained primarily nucleated epithelial cells (60\%) and few leukocytes $(10 \%)$ were classified as proestrus. Smears that contained primarily cornified cells $(90 \%)$ were classified as estrus. Smears that contained primarily cornified cells (60\%) with a significant number of leukocytes $(20 \%)$ and nucleated epithelial cells (20\%) were classified as metestrus. After cytological examination, stained smears were kept and photomicrographs were taken on a later date using Honestech TVR 2.5 software and inbuilt camera of Ultra Medical MDI microscope, (Guangzhou Keyeah Optics \& Electronics Instrument Co. LTD, China).

Animals were sacrificed a day after the last administration of extract by cervical dislocation method. Through an abdominopelvic incision, both uterine horns and ovaries were removed, cleared of exogenous tissues and weighed.

Briefly, the samples were fixed in Gender's solution for 48 hours after which they were washed in distilled water and in 50\% ethanol before re-fixing them in $10 \%$ neutral buffered formalin (Fischer et al., 2005). Samples of the left uterine horn and left ovary were grossed and processed through a 13 hour 25 minutes schedule in an automated tissue processor (SLEE MTP, Germany). Following processing, the tissues were embedded in paraffin wax and serially sectioned at $4 \mu \mathrm{m}$ using a microtome (SLEE, Germany) and stained with Haematoxylin and Eosin (H \& E).

Examination of the H\&E slides was done under a light microscope (Nikon Ci-S, type 104c), with a Nikon digital sight DS Fi camera mounted and connected to a Toshiba computer screen. The structure of the endometrium, size of the lumen, and shape of endometrial glands and the proportion of the ovarian follicles, follicular stages and corpora lutea were studied. Descriptive statistic was employed in evaluating the effects of $\mathrm{C}$. 
gynandra on the estrous cycle. An image analysis software (ImageJ) was used for the quantitative analysis of the ovarian follicles. All numerical data were expressed as mean \pm standard error of the mean (SEM), $(n=4$ rats per group), using Microsoft excel 2010. Statistical significance (p), was calculated by one-way analysis of variance (ANOVA) using Graph pad prism, version 6 . Any difference in means was further evaluated by Turkeys multiple comparison test of significance where $\mathrm{p} \leq 0.05$ was considered to be significant. Data are presented using tables and bar charts. Results from histological analyses are presented as photomicrographs and interpreted appropriately. Data for the estrous cycle of the first and last ten days of administration was assessed and compared for estrous cycle disruption.

\section{RESULTS}

A comparison of the estrous cycle of the control and treated groups revealed a mild disruption of the estrous cycle in the last ten days of the administration (Fig. 1.1a and 1.1b.) It was observed that animals in the highest treatment group $(500 \mathrm{mg} / \mathrm{kg} \mathrm{B.W}$, showed a persistent proestrous, followed by a reduction in estrous, metestrous and diestrous.

\section{Effects of C. gynandra on the estrous cycle of rats in the first ten days}

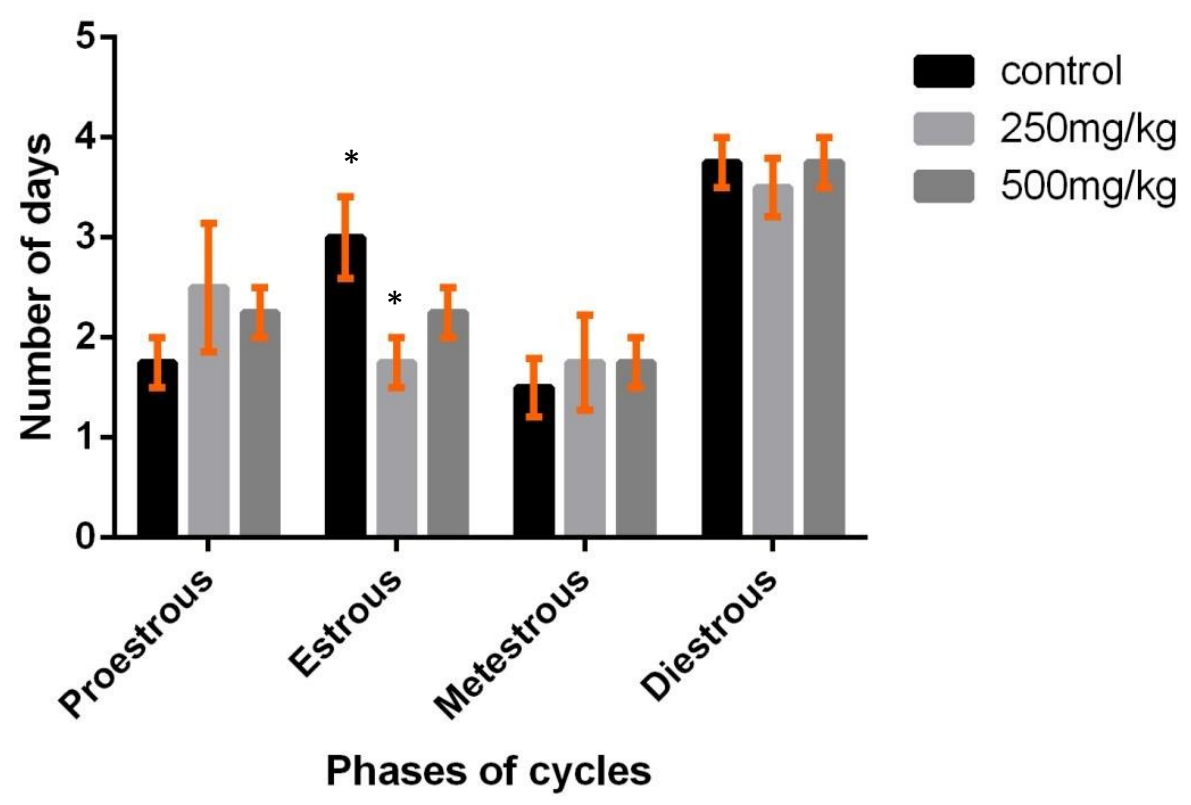

Figure 1.1a: Rats in different phases of estrous cycle during the first 10 days of the experiment. A significant difference was seen between control and the group given $250 \mathrm{mg} / \mathrm{kg} \mathrm{B.W}$ in the estrous stage $(* p=0.05)$ 


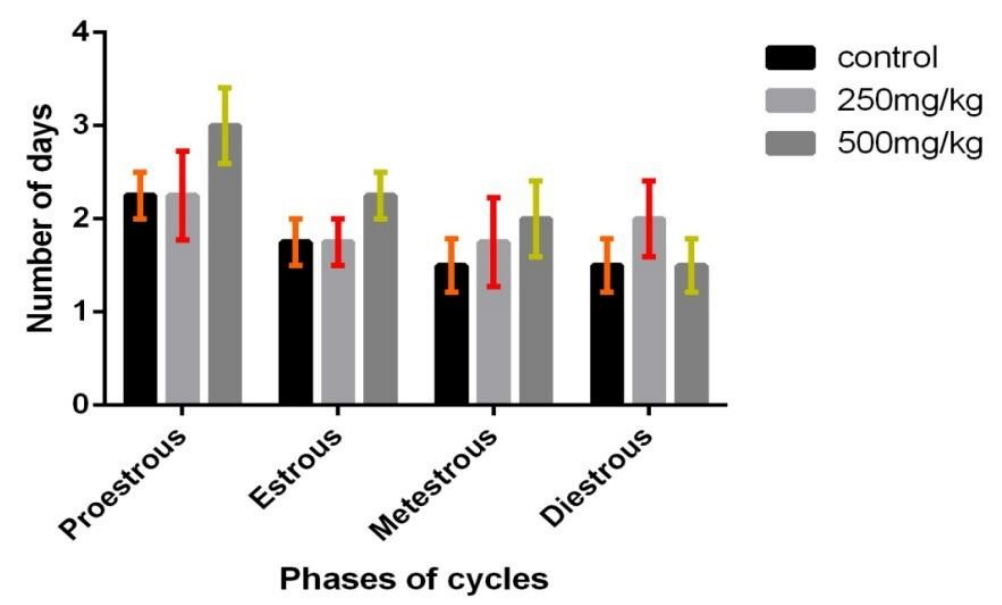

Figure 1.1b: Rats in different phases of estrous cycle during the last 10 days of the experiment. No significant change was seen between control and other treated groups ( $p>0.05)$.

\section{EFFECTS ON THE HISTOLOGY OF THE OVARY}

The ovarian interstitium from the rats in the treated groups was studded with vacuoles (Fig. 2: plates 2 and 3) as compared to the control rats (Fig. 2, Plate 1). The vacuoles become more numerous with the $500 \mathrm{mg} / \mathrm{kg}$ body weight daily dose (Fig. 2, plate 3 ). The developing ovarian follicles were more in the control rats than in the treated rats (Fig. 2).

\section{EFFECTS ON OVARIAN FOLLICLES}

The results of the ovarian follicular counting after treatment with C. gynandra are shown in table 1. In this experiment, the dose of $500 \mathrm{mg} / \mathrm{kg}$ B.W. daily, showed a significant $(p<0.05)$ decrease in secondary follicle $(1.25 \pm$ $0.25)$, when compared to that of control group $(4.00 \pm 1.22)$. The dose of $250 \mathrm{mg} / \mathrm{kg}$ body weight showed a similar decrease in primordial follicle $(2.5 \pm 1.19)$ and secondary follicle
$(3.25 \pm 0.47)$ but was not statistically significant. Similarly, a decrease in the number of primordial follicles was observed in the treated groups in relation to the control. An increase in number of atretic follicle

(2.25 \pm 1.60$)$ was also recorded in dose of $500 \mathrm{mg} / \mathrm{kg} \mathrm{B.} \mathrm{W.} \mathrm{*} \mathrm{compared} \mathrm{to} \mathrm{the} \mathrm{control*}$ (1.25 \pm 1.43$)$, most of the atresia were seen in the graafian follicles.

\section{EFFECTS ON THE HISTOLOGY OF THE UTERUS}

The endometrium of the rats treated with $500 \mathrm{mg} / \mathrm{kg} \mathrm{B.W}$, lined by simple squamous epithelium was studded with numerous large vacuoles and very few endometrial glands (Fig. $3 \mathrm{C})$. The vacuoles were not as numerous in the $250 \mathrm{mg} / \mathrm{kg}$ B.W (Fig. 2B), instead, the endometrial glands with prominent cuboidal/columnar epithelium were abundant. 

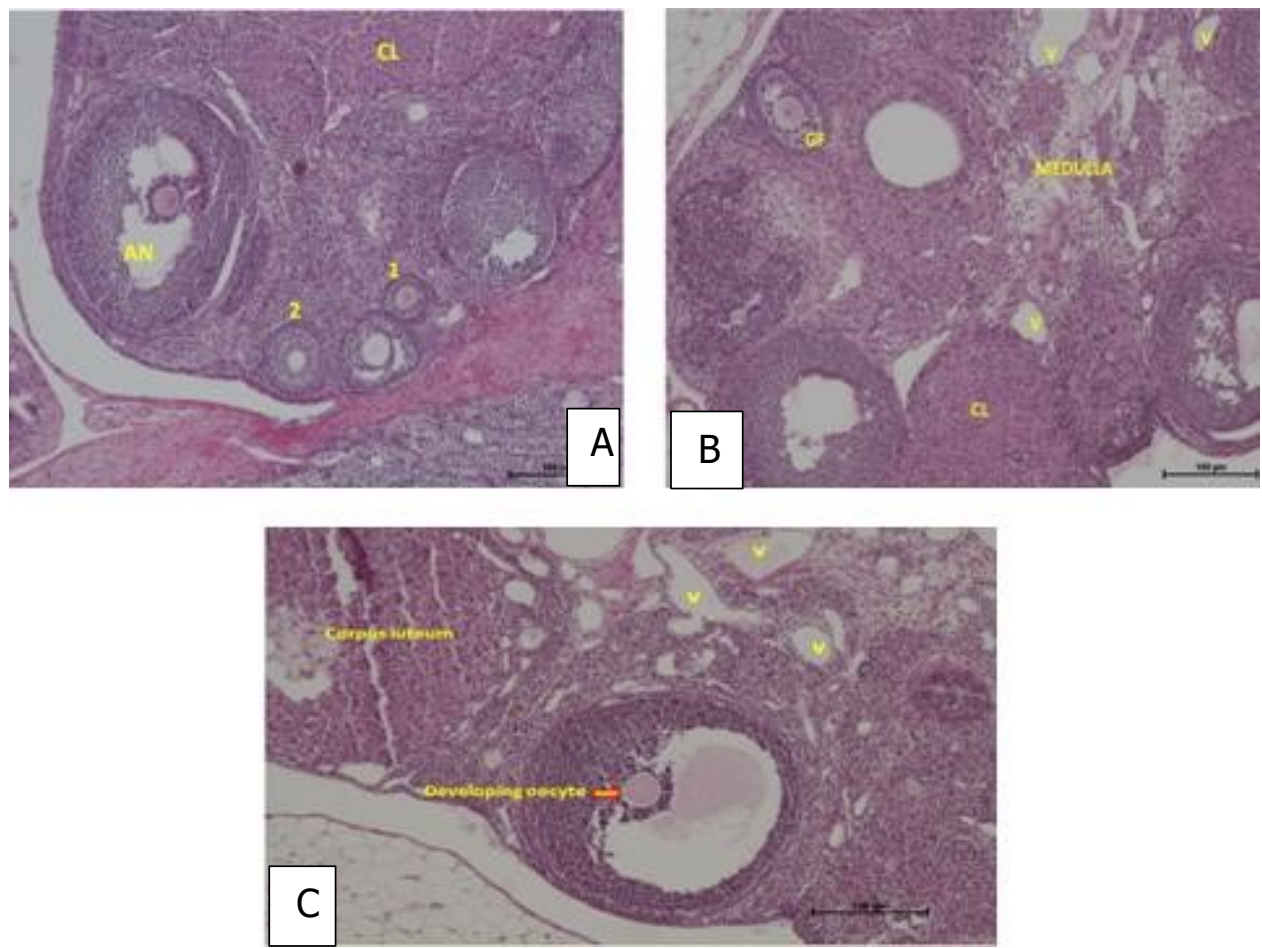

Figure 2: Transverse section through the ovary. A: Normal rat ovary, displaying oocytes at different stages of development. 1 =primary follicle. $2=$ secondary follicle, $A N=$ antral or tertiary follicle, $C L=$ corpus luteum. In $\mathbf{B},(250 \mathrm{mg} / \mathrm{kg}$ BW) and $\mathbf{C}_{\boldsymbol{r}}(500 \mathrm{mg} / \mathrm{kg} \mathrm{BW})$ note the vacuolation (V) of the interstitium, one graafian follicle (GF) and several corpora

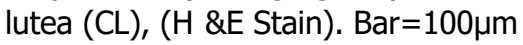

Table 1: Effects of C. gynandra on ovarian follicles after 21 days of treatment with C. gynandra

\begin{tabular}{|l|l|l|l|l|l|}
\hline \multirow{2}{*}{$\begin{array}{l}\text { Treatment } \\
\text { groups }\end{array}$} & \multicolumn{5}{|c|}{ Types of Follicles } \\
\cline { 2 - 6 } & primordial & primary & secondary & graafian & atretic \\
\hline $\begin{array}{l}\text { CONTROL } \\
1 \mathrm{ml} \mathrm{dH} \mathrm{O}_{2}\end{array}$ & $3.75 \pm 0.47$ & $\begin{array}{l}2.25 \\
\pm 0.47\end{array}$ & $4.00 \pm 1.22^{*}$ & $2.75 \pm 0.47$ & $1.25 \pm 1.43$ \\
\hline $\begin{array}{l}250 \mathrm{mg} / \mathrm{kg} \\
\text { Low dose }\end{array}$ & $2.50 \pm 1.19$ & $\begin{array}{l}2.50 \pm 0.6 \\
4\end{array}$ & $3.25 \pm 0.47$ & $2.50 \pm 0.64$ & $1.00 \pm 0.40$ \\
\hline $\begin{array}{l}500 \mathrm{mg} / \mathrm{kg} \\
\text { High dose }\end{array}$ & $1.75 \pm 0.62$ & $1.25 \pm 0.2$ & $1.25 \pm 0.25^{*}$ & $1.50 \pm 0.64$ & $2.25 \pm 1.60$ \\
\hline
\end{tabular}

Significance was estimated by Turkey'S multiple comparison test $\left({ }^{*} p<0.05\right)$. Values are shown as mean \pm SEM, $(n=4)$. 


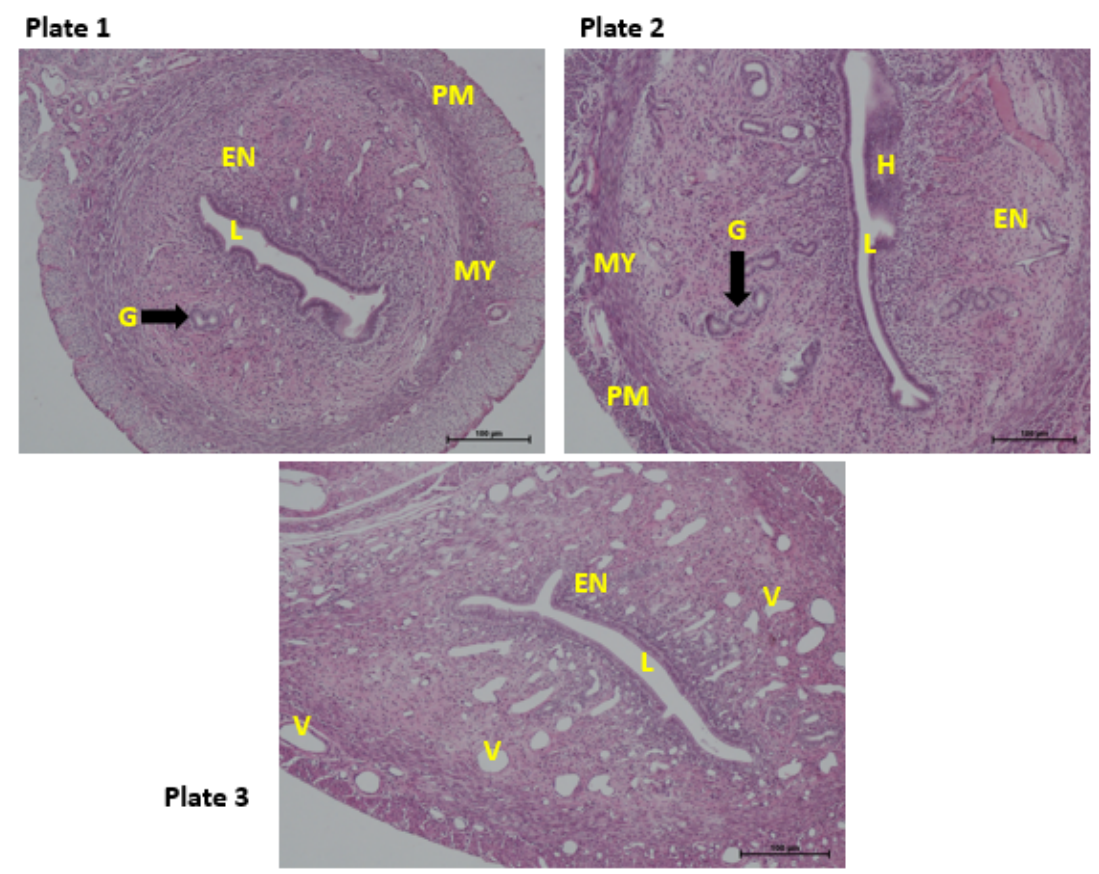

Figure 3: Transverse section though the uterus. Plate 1: Normal uterus in control group, showing dilated lumen.

Plate 2: Treated with $250 \mathrm{mg} / \mathrm{kg}$ B.W of C. gynandra, displaying hyperplasia of luminal epithelium on one side $(\mathrm{H})$, and low cuboidal/columnar glandular epithelium of endometrial glands. Plate 3: Treated with $500 \mathrm{mg} / \mathrm{kg} \mathrm{BW}$ of C. gynandra. Several vacuoles (V) are seen in the endometrium with few endometrial glands (G), (H \&E Stain). MY= myometrium; $\mathrm{L}=$ lumen; $\mathrm{V}=$ vacuoles, $\operatorname{bar}=100 \mu \mathrm{m}$

\section{DISCUSSION}

A single cycle with a diestrous period of 4 days or longer and/or an estrous period of 3 days or longer was for the purposes of toxicological assessment, considered as unusual (Goldman et al., 2007). Following the estrous cycle data in this study, a comparison between the first and the last 10 days revealed an alteration in the duration of the phases of the estrous cycle in treatment groups when compared with that of the control. The cycle status in the treatment groups (250 and $500 \mathrm{mg} / \mathrm{kg} / \mathrm{B} . \mathrm{W}$ daily) in the first 10 days of administration, was similar to the control. No striking changes were seen. Results in the last 10 days in the $250 \mathrm{mg} / \mathrm{kg}$ B.W treated group is comparable to the untreated control rats with similar changes in proestrous, estrous, metestrous and diestrous phases of the cycle. However, in the $500 \mathrm{mg} / \mathrm{kg}$ B.W treated group, a remarkable increase in the proestrous phase, followed by a decrease in estrous, metestrous and disetrous phases was observed.

Prolonged proestrous following administration of C. gynandra observed in the $500 \mathrm{mg} / \mathrm{kg} \mathrm{B.W}$ treated group, suggests a disturbance in ovulation, which is also a sign of fertility disorder probably caused by the presence of flavonoids, saponin and alkaloid components in C. gynandra leaf extract. Some of these phytochemicals have been implicated to cause disorder in estrous cycle in animals (Mustapha et al., 2011). Furthermore, data from the estrous cycle of this research agrees with Goldman et al. (2007), who stated that, substance treatment can bring about acyclicity branded by a persistent estrous, a persistent diestrus, or rather induce an irregular pattern with cycles of extended duration. The persistence in the proestrus phase seen in this study, has also been reported elsewhere by Mustapha et al.

(2011).

The overall functioning of the reproductive system is largely influenced by physiologic/endocrine hormones (Paccola et al., 2013). The cyclic changes that occur in the ovaries and uterus are controlled by the hypothalamus through Gonadotropin-releasing hormone (GnRH) (Lee and Chow, 2008). This hormone circulates in the blood and causes the release of two hormones namely; follicle stimulating hormone (FSH) and luteinizing hormone (LH) from the pituitary gland (Xia et 
al., 2013). Follicle-stimulating hormone (FSH) is produced by the pituitary gland in the first half of the menstrual cycle. It is essential for follicular development in the ovaries.

Toxicants that interfere with reproductive function can act directly on the organs of the reproductive system or indirectly through demonstrating its influence at the hypothalamic or/and pituitary gland level (Azarnia et al., 2008). During female reproductive life, most ovarian follicles undergo a degenerative process called atresia at some stage of their development, and only few follicles reach the ovulatory stage (Parimala and Kaliwal 2005). It has been shown that estrogens suppress follicular atresia and androgens enhances atresia (Billig et al., 1993). Under physiological conditions the majority of atresia occurs in secondary and tertiary follicles, while preovulatory follicles undergo a low rate of atresia (Gustavo et al., 2015). This situation was present in the control group but slightly higher in the high dose group where the majority of atresia was observed in the graafian follicles.

In vivo treatment of female rats with $\mathrm{C}$. gynandra in this study resulted in a decrease in the number of primordial, secondary and graafian follicles in both treated groups when compared to control. A statistically significant decrease in secondary follicles was seen between $500 \mathrm{mg} / \mathrm{kg}$ B.W treated group in relation to the control. Treatment of $\mathrm{C}$. gynandra probably exerted an inhibitory effect on follicle development. This would explain the observed decease in follicular development and an increase in the atresia of follicles in the high dose group when compared to the control. These effects could be due to an underlying hormonal imbalance upon administration of $\mathrm{C}$. gynandra which presents as decreased follicular development.

Similarly, in a study by Deka and Kalita, (2016), the effect of $C$. gynandra methanolic leaf extracts was evaluated on folliculogenesis in sexually matured female albino mice with regular oestrus cycle. The experimental results showed a reducing effect on follicular development with the doses of $\mathrm{C}$. gynandra leaf extract (methanolic) tested, following a treatment period of 21 days, with respect to control. Many other investigations have reported the disrupting effect of various plant extracts on ovarian folliculogenesis (Al-Qarawi et al., 2000; Solomon et al., 2010). These changes in the oocyte growth and maturation have been influenced by gonadotrophins and steroids along with growth factors which govern follicular development suggesting the possible reason of the inhibitory effect of these plant extracts on the folliculogenesis in rats.

Histological analysis of the rat uteri was conducted in the control and treated groups. Uterine histology revealed that administration of C. gynandra at doses of $250 \mathrm{mg} / \mathrm{kg} \mathrm{B.W}$ and $500 \mathrm{mg} / \mathrm{kg} \mathrm{B.W}$, resulted in a disorganized cellular structure of the endometrium and disrupted endometrial gland structure. The epithelium of the endometrial glands lengthened in the $250 \mathrm{mg} / \mathrm{kg}$ B.W group when compared to control uteri. The uteri of the control group appeared normal. Examination of the uteri of the higher treated group $(500 \mathrm{mg} / \mathrm{kg} \mathrm{B.W})$, in a larger magnification, clearly showed shortening of the epithelium of the endometrial glands, making the glands appear as cystic/vacuolated. The glands were replaced by several vacuoles. Specifically, vacuoles were obvious in the endometrial glands. Furthermore, cystic uterus and hyperplasia of cells in the uteri of treated rats were also observed. Endometrial hyperplasia is a state of excessive proliferation of the cells of the endometrium, or inner lining of the uterus. Most cases of endometrial hyperplasia is a consequence of high levels of estrogens, combined with insufficient levels of the progesterone-like hormones which ordinarily counteract estrogens' proliferative effects on this tissue (Horn et al., 2007). Endometrial hyperplasia is a major risk factor for the progress or even co-existence of endometrial cancer.

In the present study, administration of a higher dose of $C$. gynandra could be causing a reduction in the epithelium of the endometrial glands. Loss of endometrial glands epithelium is related to infertility and presents defects of implantation. This suggests that, a uterus with a low glandular epithelium cannot accommodate a developing fetus to term. An association of 
endometrial glands and infertility has also been established elsewhere (Reardon et al., 2012). This, could be one of the mechanisms by which $\mathrm{C}$. gynandra causes abortion.

From previous studies, C. gynandra plant extracts have been shown to contain phytoestrogenic compounds (Deka and Kalita, 2016). Phytoestrogenic plants, such as C. gynandra which contained saponins and flavonoids are capable of increasing the level of circulating estrogen in the female rats. The high level of estrogen prolongs estrous and proestrus phases of the estrous cycle, thereby interfering with fertility (Mustapha et al., 2011). It is believed that, these phytoestrogenic components of plants are known to reduce fertility in animals upon continuous administration. This could be the probable factors that caused disruption of estrous cycle phases that is observed in this study.

ACKNOWLEGEMENT: The authors are grateful to the staff and management of Kampala International University Western campus, for the privilege to carry out this research.

\section{REFERENCES}

1. Al-Qarawi, A. A., Abdel-Rahman, H. A., El-Badry, A. A., Harraz, F., Razig, N. A., \& AbdelMagied, E. M. (2000). The effect of extracts of Cynomorium coccineum and Withania somnifera on gonadotrophins and ovarian follicles of immature wistar rats. Phytotherapy
Research,
$14(4)$,
288-290.
http://doi.org/10.1002/10991573(200006)14:4<288::AIDPTR603>3.0.CO;2-9

2. Azarnia, M., Koochesfahani, H. M., Rajabi, M., Tahamtani, Y., \& Tamadon, A. (2008). Histological examination of endosulfan effects on follicular development of balb / c mice, (1), 33-41.

3. Billig, H., Furuta, I., \& Hsueh, A. J. W. (1993). Estrogens inhibit and androgens enhance ovarian granulosa cell apoptosis. Endocrinology, 133(5), 2204-2212. http://doi.org/10.1210/endo.133.5.8404672

4. Deka, J., \& Kalita, J. C. (2016). Effects of cleome gynandra linn . Leaf extract on ovarian folliculogenesis of albino mice. Indian journal of applied research, 6(12), 658-660.

5. Ekor, M. (2014). The growing use of herbal medicines: Issues relating to adverse reactions and challenges in monitoring safety. Frontiers in Neurology. http://doi.org/10.3389/fphar.2013.00177

6. Ekpong, B. (2009). Effects of seed maturity, seed storage and pre-germination treatments on seed germination of cleome (Cleome gynandra L.). Scientia Horticulturae, 119(3), 236- 240. http://doi.org/10.1016/j.scienta.2008.08.003

7. Fischer, A. H., Jacobson, K. a, Rose, J., \& Zeller, R. (2005). Hematoxylin and Eosin ( H \& E ) staining. CSH Protocols, 2008(4), pdb.prot4986. http://doi.org/10.1016/00165085(95)23032-7 
8. Fucic, A., Gamulin, M., Ferencic, Z., Katic, J., Krayer von Krauss, M., Bartonova, A., \& Merlo, D. F. (2012). Environmental exposure to xenoestrogens and oestrogen related cancers: reproductive system, breast, lung, kidney, pancreas, and brain. Environmental Health : A Global Access Science Source, 11 Suppl 1, S8. http://doi.org/10.1186/1476-069X-11-S1-S8

9. Goldman, J. M., Murr, Ã. A. S., \& Cooper, R. L. (2007). The Rodent Estrous Cycle: Characterization of Vaginal Cytology and Its Utility in Toxicological Studies, 97, 84-97. http://doi.org/10.1002/bdrb

10. Gustavo, L., Sim, A., Belardin, L. B., Adan, G., Chuffa, D. A., Cristina, I., \& Camargo, C. (2015). Effects of different doses of nandrolone decanoate on estrous cycle and ovarian tissue of rats after treatment and recovery periods. International Journal of Experimental Pathology, (96), 338-349. http://doi.org/10.1111/iep.12144

11. Horn, L. C., Meinel, A., Handzel, R., \& Einenkel, J. (2007). Histopathology of endometrial hyperplasia and endometrial carcinoma. An update. Annals of Diagnostic Pathology. http://doi.org/10.1016/j.anndiagpath.2007.05.002

12. Kalita, J. C. (2014). Zoology Phytochemical Screening of the Leaves of Cleome Gynandra Linn ( Cleomaceae ) Jupitara Deka, (7), 291-293.

13. Kamatenesi-Mugisha, M., \& Oryem-Origa, H. (2007). Medicinal plants used to induce labour during childbirth in western Uganda. Journal of Ethnopharmacology, 109(1), 1-9. http://doi.org/10.1016/j.jep.2006.06.011

14. Knapp, K. M., Brogly, S. B., Muenz, D. G., Spiegel, H. M. L., Conway, D. H., Scott, G. B., ... Read, J. S. (2012). Prevalence of congenital anomalies in infants with in utero exposure to antiretrovirals. The Pediatric Infectious Disease Journal, 31(2), 164-70. http://doi.org/10.1097/INF.0b013e318235c7aa

15. Lee, V. H. Y., Lee, L. T. O., \& Chow, B. K. C. (2008). Gonadotropin-releasing hormone: Regulation of the GnRH gene. Journal. http://doi.org/10.1111/j.17424658.2008.06676.x

16. Mclean, A. C., Valenzuela, N., Fai, S., \& Bennett, S. A. L. (2012). Performing Vaginal Lavage , Crystal Violet Staining, and Vaginal Cytological Evaluation for Mouse Estrous Cycle Staging Identification, (September), 4-9. http://doi.org/10.3791/4389

17. Mishra, S. S., Moharana, S. K., \& Dash, M. R. (2011). Review on cleome gynandra. International Journal of Research in Pharmacy and Chemistry, 1(3), 681-689.

18. Mohammed, A., Ibrahim, M. A., \& Islam, M. S. (2014). African medicinal plants with antidiabetic potentials: A review. Planta Medica. http://doi.org/10.1055/s-0033-1360335

19. Moshi, M. J., Otieno, D. F., \& Weisheit, A. (2012). Ethnomedicine of the Kagera Region, north western Tanzania . Part 3: plants used in traditional medicine in Kikuku village, Muleba District. Journal of Ethnobiology and Ethnomedicine, 8(1), 14. http://doi.org/10.1186/17464269-8-14

20. Mustapha, A. R., Bawa, E. K., Ogwu, D., Abdullahi, U. S., \& Kaikabo, A. A. (2011). Effects of ethanolic extract of Rhynchosia sublobata ( Schumach ) Meikle on estrous cycle in Wistar rats. iIternational Journal of Med. Arom. Plants, 1(2), 122-127.

21. Namulindwa, A., Nkwangu, D., \& Oloro, J. (2015). Determination of the abortifacient activity of the aqueous extract of Phytolacca dodecandra ( $L$ ' Her ) leaf in Wistar rats, 9(3), 43-47. http://doi.org/10.5897/AJPP2014.

22. Paccola, C. C., Resende, C. G., Stumpp, T., Miraglia, S. M., \& Cipriano, I. (2013). The rat estrous cycle revisited : a quantitative and qualitative analysis. Animal Reproduction, 10(4), 677-683.

23. Parimala M. D.and Kaliwal B. B. (2005). Dose-Dependent Estrous Cycle, Ovarian Follicles and Biochemical Contents Reversal in Albino Mice after Exposure to Mancozeb. Caspian Journal of Environmental Sciences (CJES), 3(2).

24. Reardon, S. N., King, M. L., MacLean, J. A., Mann, J. L., DeMayo, F. J., Lydon, J. P., \& Hayashi, K. (2012). Cdh1 Is Essential for Endometrial Differentiation, Gland Development, and Adult 
Function in the Mouse Uterus. Biology of Reproduction, 86(5), 141-141. http://doi.org/10.1095/biolreprod.112.098871

25. Robinson, M. M., \& Zhang, X. (2011). the World Medicines Situation 2011 Traditional Medicines: Global Situation, Issues and Challenges. World Health Organization, (3rd Edition), 1-14.

26. Singh, S., Moore, A. M., Bankole, A., Mirembe, F., Wulf, D., \& Prada, E. (2006). Unintended Pregnancy And Induced Abortion In Uganda. Guttmacher Institute,NY, (0-939253-89-5).

27. Solomon, T., Largesse, Z., Mekbeb, A., Eyasu, M., \& Asfaw, D. (2010). Effect of Rumex steudelii methanolic root extract on ovarian folliculogenesis and uterine histology in female albino rats. African Health Sciences, 10(4), 353-361.

28. Thomford, N. E., Dzobo, K., Chopera, D., Wonkam, A., Skelton, M., Blackhurst, D., ... Dandara, C. (2015). Pharmacogenomics Implications of Using Herbal Medicinal Plants on African Populations in Health Transition. Pharmaceuticals (Basel, Switzerland), 8(3), 63763. http://doi.org/10.3390/ph8030637

29. Tropp, J., \& Markus, E. J. (2001). Effects of mild food deprivation on the estrous cycle of rats. Physiology \& Behavior, 73(September 2000), 553-559.

30. WHO. (2005). World Health Organization: National policy on traditional medicine and regulation of herbal medicines- report of a WHO global survey. Who, (May), 156. 